\title{
Intergenerational Real Wages, Technological Change, and Economic Growth in Colombia
}

\author{
Fernando Mesa \\ Department of Economics and Business, Jorge Tadeo University, Bogotá, Colombia \\ Email:fmesaparra@gmail.com,fernandog.mesap@utadeo.edu.co
}

Received 20 November 2015; accepted 14 February 2016; published 17 February 2016

Copyright (C) 2016 by author and Scientific Research Publishing Inc.

This work is licensed under the Creative Commons Attribution International License (CC BY). http://creativecommons.org/licenses/by/4.0/

(c) (i) Open Access

\section{Abstract}

This paper focuses on the decomposition of real wages in Colombia both by workers' ages and by cohorts, which overlap over time. The paper analyses how the Colombia's labour structure has undergone important changes in the period 1982-2007. This period has been characterized by a demographic transition that has tilted the balance from a relatively young population to an older one. The effects of capital accumulation have been estimated and modelled considering the presence of ever more sophisticated machinery, usually replacing less-skilled, younger workers, in relation to older and more qualified ones. In general real wages present a curved shape for each generation, as is acknowledged in the life-cycle hypothesis, according to which people generally start their working life with low incomes and rising debts and then obtain higher income and accumulate assets.

\section{Keywords}

Human Capital Skill Occupational Choice Labour Productivity, Demographic Trends, Macroeconomic Effects, Wage Levels and Structure Wage Differentials

\section{Introduction}

During the period 1982-2007, the economic growth rate in Colombia has been characterized by three main phases: low real income growth from the 1980s to the mid-1990s, stagnation and recession in the late 1990s, and a subsequent recovery and consequent accelerated economic growth continuing into the late 2000s. These economic outcomes should be related to changes in labour productivity measured in terms of real wages taken as a proxy for productivity. Obviously, there should be a close relationship between real wages in an economy and 
its economic growth. One of the most important factors to explain economic growth in the long run is increasing labour productivities.

The main purpose of this paper is to measure the life-cycle productivity profiles of Colombian workers from 1982 to 2007 in accordance with workers' ages and cohorts, with real wage information obtained from household surveys collected by the Colombian Statistics Office. Thus, this analysis will contribute to understanding the dynamics of the Colombian economy with an approach of overlapping generations in the referenced period. A small number of studies in Colombia have explored changes in real wages by age and cohort over time ${ }^{1}$. This paper attempts to document these changes in productivity for Colombian workers in a long-run period.

The paper contributes to explaining the effects that the introduction of new machinery has on the unskilled labour saving, especially related to the new generations, who are both in disadvantage as consequence of their inequality conditions, and for his greatest skill requirements. This characterization is complemented with the most appropriate theoretical tool, overlapping generation models, which allows obtaining stylized facts through the introduction of twelve worker cohorts. This analysis shows the need to rethink the policy to qualify younger workers to match the new job demands.

Different productivity results by population subgroups, defined by their position in the labour market, might have been registered in this period. The conjecture is that productivity decomposition, according to workers' ages and by cohorts of Colombian households, may reveal significant differences in the dynamics of workers' real wages, and that young workers are the losers with respect to middle-aged workers.

The hypothesis is that technology substitutes unskilled labour and is complementary with skilled workers, and that this technological bias affects real wage rates. Kotlikoff and Sachs [2], like other authors in the extensive literature related to the economic history ${ }^{2}$, have argued that new machines replace unskilled labour; as such the new technology is designed and operated by new skilled workers. For that very reason, it is not surprising that the real wage gap between skilled and unskilled workers has increased, as has been observed in the Colombian economy in the recent decades.

Kotlikoff and Sachs [2] also suggested that the new technology would bring new threats to workers, in the sense that people would require both more time for education and to gain work experience in order to be considered qualified in the labour market. Therefore, the most skilled workers will age, and their levels of income and wealth will be higher with respect to younger workers.

When machines get smarter, older skilled workers will get richer, in contrast with young workers who are paid relatively lower real wages; thus there is an unfavourable distribution with regard to younger and less skilled workers. Highly educated workers will enjoy more opportunities, but workers with less education and experience will face declining employment prospects and stagnant incomes.

In this line of reasoning, this paper assumes the existence of different types of labour as production factors: The degree of unskilled and skilled labour depends on ages; less-skilled workers tend to be younger while more-skilled workers tend to be middle-aged. In addition, capital stock is introduced in the model that is presented in the last section, although it will not consider capital's different qualities. For that section, new technology is embodied in capital goods, using more skilled labour and saving unskilled labour. The factor prices are determined by their marginal productivity, so that a factor-saving innovation, as it is the case of unskilled worker factor, reduces both its relative price and the share of income in the economy.

Higher productivities registered during the Colombian life-cycle (by age groups as well as by different cohorts) are achieved consequently through work experience and, in many cases, by upgrading labour qualifications $^{3}$. It is expected that skilled workers in recent cohorts should be more productive than their predecessors were at the same stage due to new technology and access to higher and better quality education. It is also expected that new social and cultural environments elicit new and better skills from workers, who also have access to better technologies for their job performance. Unskilled workers, on the contrary, cannot benefit relatively from these improved socio-economic conditions as a result of a capital technology bias that tends to replace this factor.

The initial hypothesis is that recent cohorts of skilled workers present higher productivity; while the produc-

${ }^{1}$ Guataquí, García and Rodríguez [1] study the education and age effects in determining labour income, where the age effect increases the incomes according to a concave function. In addition they study these effects when workers are disaggregated between employees and self-employed.

${ }^{2}$ Literature includes the works of Baldwin and Martin [3]; and Williamson [4]. The difference is that in the past new technology usually raised all real wages, and now it is biased to empower the most talented individuals and against the rest of population (The Economist [5]).

${ }^{3}$ Becker [6] made this point in his classic book on human capital. 
tivity curve shape will remain approximately equal across cohorts. Notwithstanding, younger and less skilled workers could record lower productivities with respect to previous cohorts in some periods.

The empirical evidence shows that individuals in the same cohort go through a learning curve which results in higher productivity levels as workers advance in the labour life-cycle, meaning that present productivities of skilled workers are higher than those of previous cohorts. It is expected that maximum productivity is obtained by middle-aged workers while older workers tend to move into a transition phase of decreasing productivities. Productivities tend to fall at the end of an active life which could be reflected in the economy's slower growth.

There are studies that examine household income for different economies. Smeeding and Sullivan [7] explored the relative median incomes for different age groups in four developed countries: Canada, Sweden, the United Kingdom, and the United States. They took the disposable incomes after taxes, and these were adjusted by public transfers in the period 1989-2004; they also analysed how revenue performance was affected by labour market conditions, changes in social security entitlements as well as housing costs.

Beaudry and Green [8] documented changes in the age-earnings relationship across different cohorts in Canada, using income patterns of cohorts to evaluate the hypothesis about the labour-skills bias that accompanied changes in labour demands. Bertola and Villa [9] studied the gains or losses of Italian incomes among young and old cohorts over the period 1989-2004, and they described the difficulties faced by young generations as a result of different simultaneous events, such as the economy's general low performance, institutional changes in the labour market, new reforms in the pension system, and exceptional increases in the cost of housing.

Deaton and Paxson [10] [11] analysed how saving by household heads varied over the life-cycle. Their analysis implied problems when transferring demographic predictions for households into predictions for individuals. Their interest was focused on whether changes in the demographic structure as well as age affected household heads' decisions regarding saving. Thus they connected economic growth and savings and considered whether these were affected by changes in the household demographic structure ${ }^{4}$.

Four sections follow this introduction. In the next section I discuss the statistical limitations for explaining changes in the labour productivities. While Section 3 contains analyses of labour productivity decomposition measured in terms of real wages for 80 cohorts of workers between 17 and 72 years of age as well as considering the trend in real wages during the period. In the Section 4, average cohort productivities are compared, both for the total economy and in terms of the industrial and services sectors; in addition, panel data models are estimated to account for changes in real wages between age groups and cohorts for the period considered. In Section 5, a simplified overlapping generation model is constructed to illustrate the typical Colombian life-cycle in a five-year intervals scheme, and the effects that arise by an increase in the capital stock efficiency. The last section is devoted to conclusions.

\section{Household Data}

As noted above, the dynamic economic growth rate should be correlated with the productivity, real wages as a proxy, reflected in the life-cycle of workers and by productivity increases among recent cohorts. Hence, one must measure productivity profiles according to workers' ages and also by the changes in productivity exhibited by recent cohorts. Necessarily, the productivity series or real wages should take into account a third element, which is trend. All these factors are purely empirical.

Real wages are analysed from ages 17 to 72, and few workers outside of that range are expected to make any significant economic contribution. Household surveys have been collected quarterly by the Colombian Statistics Office since its inception; and these have been collected on a monthly basis after since 2000. For the purposes of this study's purposes, the data is has been processed quarterly over 25 years and as well as for 80 overlapping cohorts for the referenced period.

The different households surveyed are chosen randomly and so it is not possible to follow individuals over the time frame. However, it is possible to follow groups of people with similar characteristics. The surveys used in this study follow cohorts of individuals over time, with cohorts defined according to birth date. The successive surveys let us to follow the cohorts, their real wages, education levels, and occupation types.

It is important to point out briefly some shortcomings in measuring productivity changes by using real wages

${ }^{4}$ Mesa, Sánchez and Zarta [12] explain the relationship between external debt and economic growth in Colombia with a model of overlapping generations. A comprehensive discussion on regarding the different dimensions of household survey analysis and the interrelationships of the dynamics is can be found in Attanasio and Székely [13]. 
as a proxy. It is well-known that the officially-reported real wages are not necessarily those that clear the actual labour market. Other factors regarding market labour failures are the imperfect mobility of labour as well as wage inflexibility attributable to institutional constraints, such as the minimum wage. Nevertheless, theorists agree that there must be a clear relationship between labour productivity and real wages ${ }^{5}$.

Although household surveys obtain household income, it is difficult to attribute income to individuals, especially when the greatest resource for a household is a family business. Since household income in this study is strictly related to wages, this problem is minimized here, in contrast to studies that examine consumption and savings in the family life-cycle, where individuals of different ages coexist in the same household (Deaton and Paxson [10]. Thus household consumption combines information from individuals in different life stages, which obscures the link between consumption, and saving with the individual age profiles.

This paper examines changes in worker productivities in seven Colombian metropolitan areas by considering the following:

1) Changes in the demographic structure of the labour market explained by population growth and unemployment rates.

The demographic pattern affects productivity in accordance with the age profiles of the workers. A lower rate of population growth means there are fewer young workers than middle-aged ones, which leads to an increase in the share of workers that record higher productivities (i.e., the middle-aged). When elderly workers increase their participation, the overall labour productivity tends to decrease along with the economy's growth rate.

Additionally, a reduction in the unemployment rate explains higher economic growth rates as a result of higher total employment. Regarding the latter, it is expected that the economic process preferentially incorporates the unemployed with the highest levels of productivity for each type of activity required.

2) Productivity by age profiles for different worker groups.

The conjecture is that recent cohorts, especially for skilled workers, present higher productivity profiles. However the shape of the productivity curve does not change, though it may tend to be steeper.

3) It is expected that the industrial sector should record higher levels of productivity than service activities, at least in countries like Colombia where the service sector is intensive in the use of unskilled labour. It is important to note that agriculture in Colombian household surveys shows a positive bias to use more skilled workers, as data are has been collected from the urban population.

In addition to educational levels and unemployment rates obtained from the surveys, organized by age and cohort, two additional macroeconomic variables are included in the forthcoming econometric models. These are capital stock and the degree of the openness of the Colombian economy, defining the latter as international trade in terms of GDP. These two quarterly macroeconomic variables are constructed with information obtained from the Colombian National Department Planning. Necessarily, physical capital accumulation, which enables the adoption of the production methods of the countries with major advances in technology, should impact labour productivity. This process of technological convergence might be favoured by the trade openness among countries.

\section{A Standard Approach about Colombian Life-Cycle Theory and Real Wages as a Proxy for Productivity}

The analysis in this section is developed in terms of workers without reference to households. I first discuss how changes in the Colombian demographic structure and labour market affect productivities and also how the real wage series are decomposed in three effects: age, cohort and trend. Second, I discuss the productivity dynamics in the manufacturing and service sectors, and then panel data models are estimated to account for the effects on real wages by age profiles and by cohorts.

\subsection{Colombian Demographic Structure and Real Wages Decomposition}

\subsubsection{Colombian Demographic Structure}

If very young and elderly workers show low productivity levels and are potentially dissaving then a reduction in this group of workers in the labour demographic structure can explain an increase in economic growth. Changes in demographic structure can indeed exert potentially large effects on national productivity and, thusly, on eco-

\footnotetext{
${ }^{5}$ Analytically, real wages must be equal to their productivity in equilibrium; regrettably, this does not correspond with reality because of market imperfections. But in the long run productivity movements should attract movements in real wages.
} 
nomic growth rates. Increases in the number of people who exhibit higher productivity, presumably those in middle age, relative to those who show low productivities, the younger as well as elderly workers, can potentially explain a greater dynamic in economic activity.

Thus, increasing the labour share of those with higher productivity levels makes economic growth accelerate. Therefore, the life-cycle hypothesis leads to a rich set of predictions about the interaction between age structures, productivity and economic growth over time.

The labour structure in the biggest seven Colombian cities labour structure for a period of 25 years (1982 to 2007) is reported in Table 1. Each cohort of workers begins at age 17. The share of the younger workers, between the ages of 17 and 26, shows a clear downward trend in this period. They lose about 11 percentage points in the labour demographic structure. In contrast, middle-aged workers, between the ages of 42 and 52, increase their participation by about 6 percentage points. Additionally, the oldest workers, between the ages of 62 and 71, continually increase their share in the labour demographic structure even though this population has traditionally contributed less than three percentage points to the total working population.

One might expect the average productivity during the reference period to have increased significantly. However, as will be shown later, that was not the case.

\subsubsection{Real Wages Decomposition}

As a proxy for productivity, the real wage series are disaggregated into the three components of cohort, age and trend. These three factors are obtained by estimating a statistical model (Equation (1)) where the dependent variable is the logarithm of real wages and the explanatory variables are three sets of dummies related to cohorts, ages and time. The decomposition methodology written in matrix terms is:

$$
\ln w=D^{\alpha} \alpha_{\alpha}+D^{c} \beta_{c}+D^{t} \gamma_{t}+u_{\omega},
$$

where $w$ represents the real wages corresponding to each individual, $D^{\alpha}$ a matrix of 56 age dummies, $D^{c}$ a matrix of 80 cohort dummies, and $D^{t}$ a matrix of 25 -year dummies ${ }^{6}$.

Each dummy by cohort corresponds to the consecutive ages of a cohort over time. Similarly, the age dummies relate to workers who are the same age during the reported period. The data is organized into pairs of ages and cohorts, so that each pair of observations corresponds to a specific quarter. Coefficients $\alpha_{\alpha}$ and $\beta_{c}$ represent the edge and cohorts effects over labour productivity. The coefficient $\gamma_{t}$ is the time effect, and $u_{w}$ is the measurement error. As usual, one column must be dropped from each of the three matrices. However, as explained in Deaton [14], even after dropping these columns, it is still impossible to estimate Equation (1) because there is an additional linear relationship across the three matrices. So to estimate this model it is necessary to drop one more column from any of the three matrices, the time dummies matrix in this study.

Table 1. Demographic structure of employed people after aged 17.

\begin{tabular}{cccc}
\hline Generation & $1982-1987$ & $1992-1997$ & $2002-2007$ \\
\hline $17-21$ & 12.7 & 9.7 & 7.6 \\
$22-26$ & 20.1 & 16.9 & 14.6 \\
$27-31$ & 16.4 & 17.3 & 13.8 \\
$32-36$ & 14.0 & 16.1 & 14.2 \\
$37-41$ & 10.7 & 12.6 & 13.7 \\
$42-46$ & 8.6 & 9.6 & 12.2 \\
$47-51$ & 6.4 & 6.7 & 9.2 \\
$52-56$ & 5.2 & 4.9 & 6.8 \\
$57-61$ & 2.7 & 2.8 & 3.6 \\
$62-66$ & 1.7 & 1.9 & 2.3 \\
$67-71$ & 0.8 & 0.8 & 1.1 \\
72 and more & 0.7 & 0.7 & 1.0 \\
\hline
\end{tabular}

Source: DANE, household surveys.

${ }^{6}$ Even though the time series frequency is in terms of quarters, it is more appropriate to take the time in years for consistency in ages and cohorts. 
Figure 1 illustrates worker productivity levels by cohort, where the highest values are for cohorts born recently. The ordinate of the graph relates the $\beta_{c}$ value of the dummy for each of the 86 cohorts. Workers born before the 1950s show increasing productivity; while workers born from the 1950s to the late 1970s exhibit decreasing productivities.

The latest cohorts analysed, the workers born in the 1980s, tend to have recovered the productivity levels. The most recent cohorts were excluded from the analyses as their short active labour life does not allow inferences regarding their productivity results.

The typical productivity profile by age is presented in Figure 2. Real wages, as proxies for productivity, show the standard life cycle. Productivity per worker increases up to the age of fifty, and then it tends to start dropping slowly; where real wages of workers aged sixty are higher than those of workers aged thirty. These results explain age productivity profiles for the different cohorts.

As shown above, workers' productivity rises up to age 40, then it remains stable for a number of years. At 40 , workers are about 5 per cent more productive than those who are 35 years old; while, workers aged under 30 are 15 to 25 per cent less productive than those who are 35 years old.

Notably, the productivity curve moves upward over time if economic growth is high, so that each cohort reaches better living standards than its predecessors. In contrast, the productivity curve moves down if the economic situation is in a stagnation phase or an economic depression.

Note the existence of the hypothesis of pro-cyclical movements between labour productivity and economic activity. Productivity fluctuates according to the state of the business cycle, so that it increases when the economy

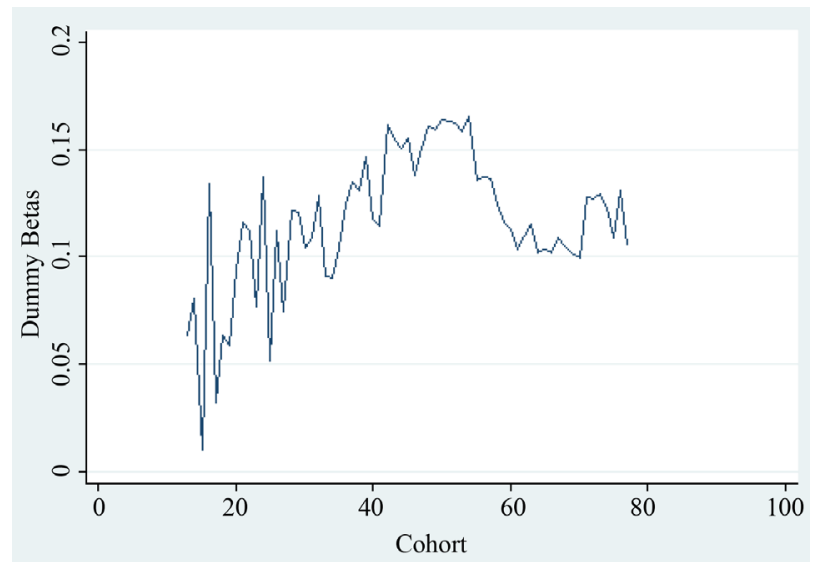

Figure 1. Cohort effects. Note: The ordinate axis relates the estimated parameters of the dummies for cohort effects $\left(\beta_{c}\right)$ in Equation [1].

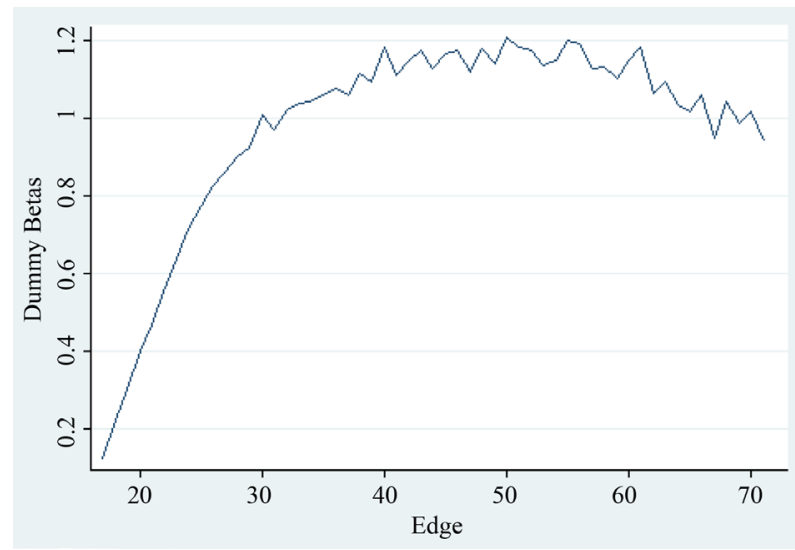

Figure 2. Aged effects. Note: The ordinate axis relates the estimated parameters of the dummies for age effects $\left(\alpha_{\alpha}\right)$ in Equation [1]. 
is expanding and as well as when the potential production capacity is used; conversely, it falls in economic downturns (Biddle [15]).

The different phases of the Colombian economy in the nearly two and a half decades studied are identified in Figure 3. At the end of the 1990s, the economy declined sharply and there was economic stagnation. That crisis was preceded by a phase of rising labour productivity. After the recession of 1998-1999, analysts expected a strong improvement in productivity but the actual recovery was slow and volatile. Figure 3 excludes the cohort and age productivity effects, to leave only the time effect.

\subsection{Aggregated and Sectorial Productivities Using an Approach of Overlapping Cohorts}

The first purpose of this section is to document how worker productivities change among successive cohorts. The second is to examine how the industrial and service worker productivity profiles change among different cohorts. Subsequently, how real wages or productivities change according to ages and by cohorts for the period 1982-2007, and are examined statistically using panel data models.

\subsubsection{Labour Productivity Changes in the Industrial and Services Sectors Related to the Cohort Profiles}

As several cohorts live in the same period, Figure 4 presents three cross sections every ten years, averaging five years. Cohorts of workers are grouped into ranges of five years so that there are twelve cohorts for each crosssection.

As shown in Figure 4, workers' real wages in the twelve cohorts during 1992-1997 were generally higher

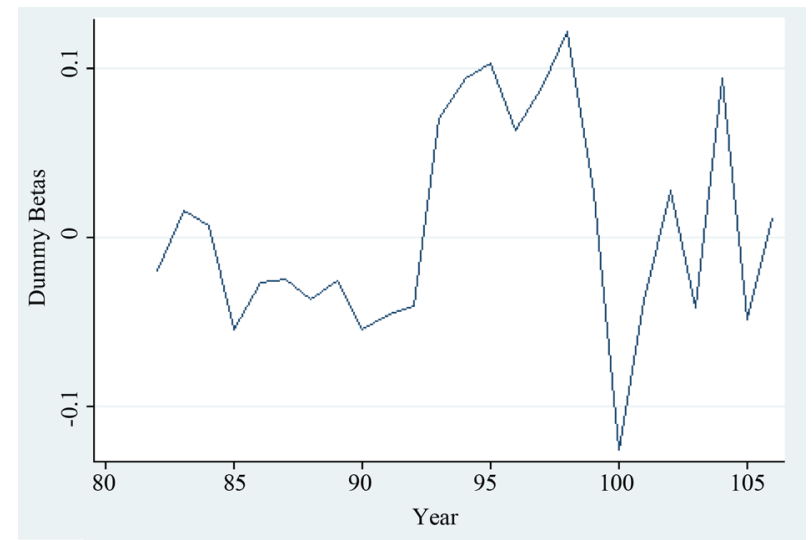

Figure 3. Time effects: 1982-2006. Note: The ordinate axis relates the estimated parameters of the dummies effects for time $\left(\gamma_{t}\right)$ in Equation [1].

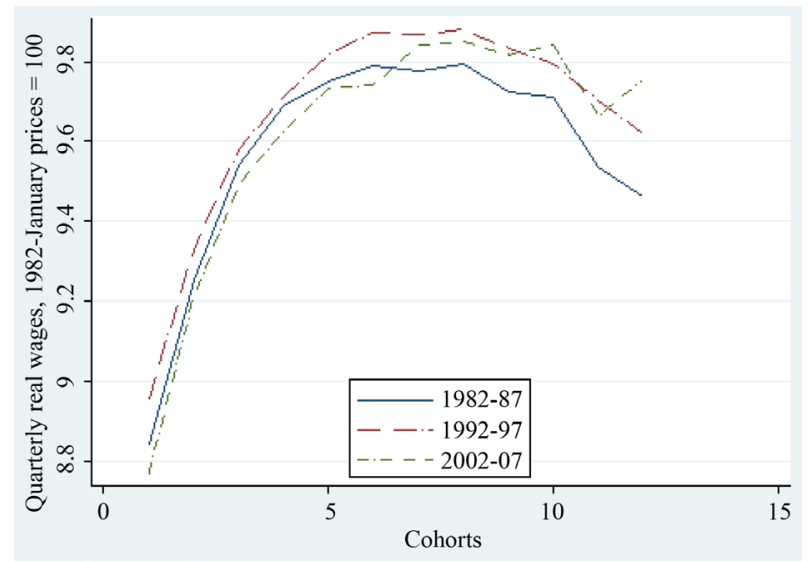

Figure 4. Aged effects: five-year-periods. 
than in the other two periods. As has been mentioned above, registered economic growth rates in this economic period were relatively high, especially for middle age workers. In the period 2002-2007, the productivities of workers less than fifty years old were lower than those recorded in the two previous periods (1982-1987 and 1992-1997). But workers with over aged 50 recorded relatively higher real wages than levels that had been previously achieved.

Older workers in the last period were able to recover their real wages and productivity levels as they lived in a favourable economic growth phase when investment rates were increased. Younger and some middle-aged workers were paid less during 2002-2007 than their counterparts in previous periods. In general, recent cohorts of young workers saw their real wages and productivities decreased in comparison with cohorts of an older age. It is critical to understand that economic growth must be explained by additional factors, in this case, the reduced unemployment rate and concomitant growth in the number of workers.

An important portion of the analysis is to identify cohort productivity patterns for industry and service sectors. The service sector is defined here in terms of the following activities: financial and commercial services, restaurants and hotel management and transport.

Figures 5-7 show that the industrial sector was not the leading sector in the economy during the periods considered. Figure 5 exhibits the real wages, as a proxy of productivities, in the industrial and service sectors for the period 1982-1987. Similarly, Figure 6 and Figure 7 show the productivities for the periods 1992-1997 and 2002-2007.

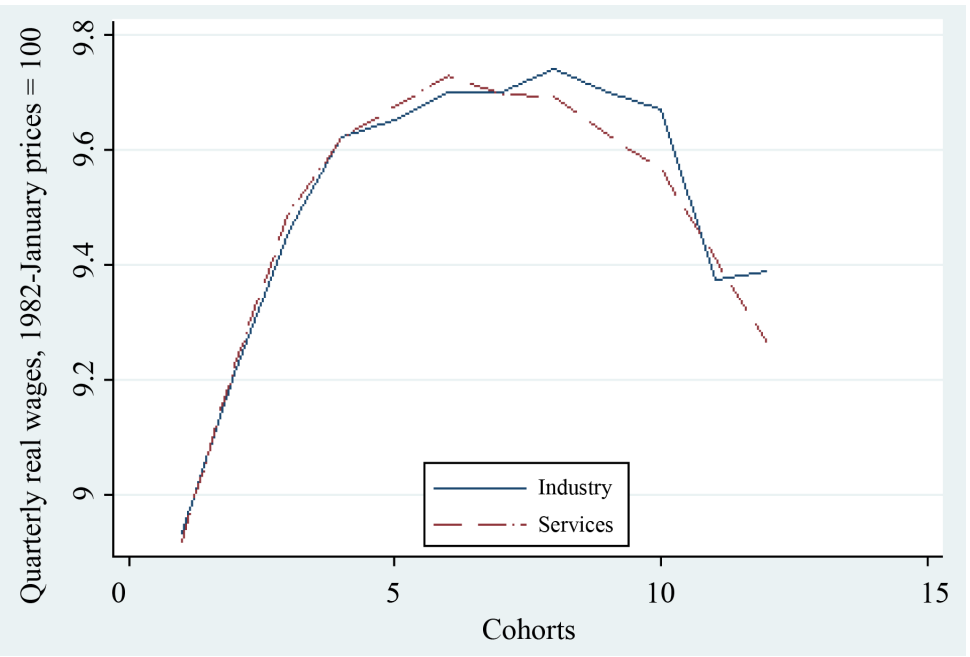

Figure 5. Aged effects: Industry and services 1982-1987.

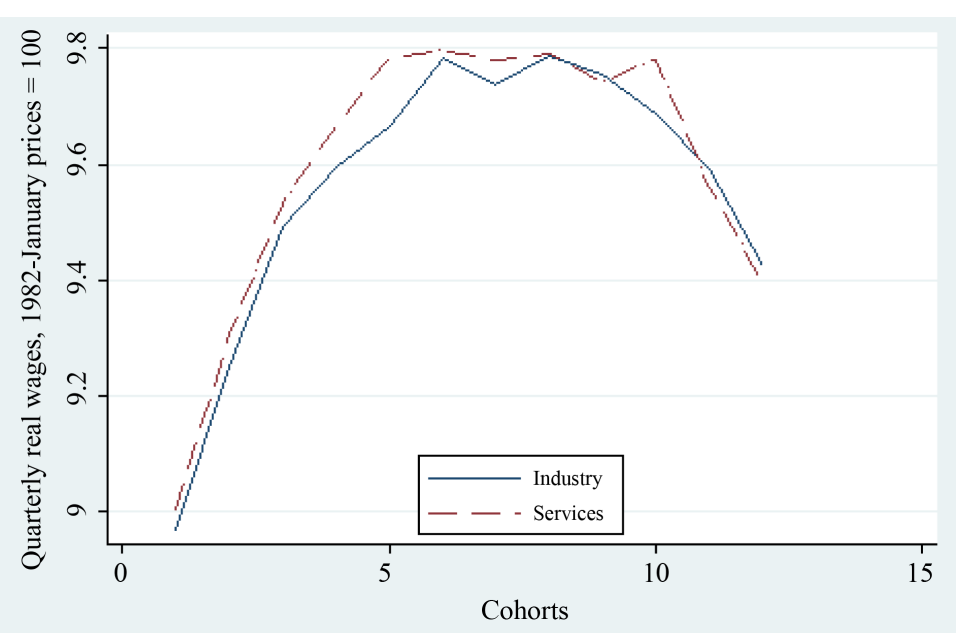

Figure 6. Aged effects: Industry and services 1992-1997. 


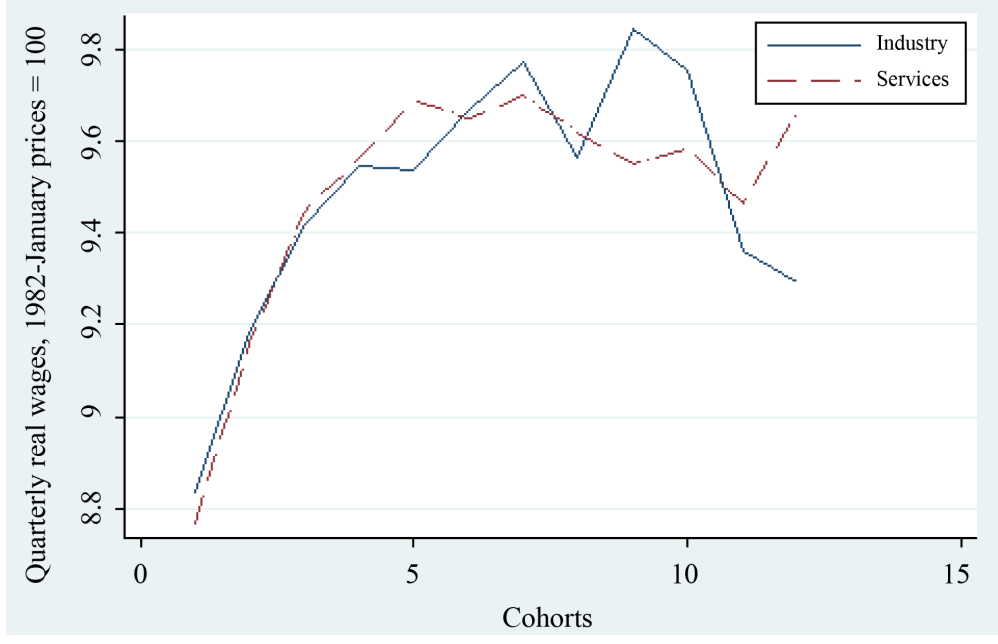

Figure 7. Aged effects: Industry and services 2002-2007.

In the first period (1982-1987) the industrial sector's productivity levels were slightly lower than those for the service sector, although its cohorts over fifty were superior in terms of productivity. In the period 1992-1997 the industrial sector's productivities were still lower than those in the service sector. For the period 2002-2007 industrial and services productivities show the same pattern. Overall, the curve shape for industrial productivity is approximately similar to that for services.

A key point is the analysis of the density functions for productivities. By way of illustration, Figure 8 shows three histograms (kernels) of the real wages for the cohorts representing those from 42 to 47 years old. The histograms apply to the following three periods: 1982-1987, 1992-1997 and 2002-2007. "Kernels" are histograms with continuous approximations, performed through semi-parametric regression method.

The histograms (kernels) for the three referenced periods (Figure 8) exhibit two important facts. First, the real wages or productivities increase. This aspect is shown when the density functions are displaced toward the right. And second, functions tend to be pointed (kurtosis), and therefore the dispersion of real wages is smaller, in this case for workers aged $42-47$.

\subsubsection{Savings, Capital Accumulation and Productivity}

In highly stylized life-cycle model, young and middle-aged workers' productivity curve, the real wages curve, has a positive slope that allows these workers to save and accumulate assets for their retirement years, but this also allows the possibility of an inheritance for new generations. In general, the age profile curve exhibits a bending shape that moves up or down according to the real business cycle. That curved shape also explains the aggregate saving-investment levels in the economy.

Empirical evidence indicates that there is a redistributive effect against unskilled workers, caused by the capital accumulation process that incorporates new technologies saving unskilled labour, particularly those represented by young workers. These workers should save as much as they can to become more qualified and to acquire new capital. However, these young workers' relative earnings become relatively lower and, thus, they save less in relation to the resources that they really need in order to escape from poverty.

In this sense, an econometric approach is used in which the dependent variable is the monthly real wages measured in each quarter. The effects of labour experience and schooling on labour income are separated, where age is taken as the potential of labour experience ${ }^{7}$.

Table 2 lists other additional economic factors that explain changes in real wages according to ages and working experience. Real wages must be negatively related to the unemployment rate, while being positively related to the physical capital accumulation logarithm and to an index of economic openness, all variables which are considered in quarterly terms.

Panel data estimation technical is applied for the following model:

${ }_{7}^{7}$ Obviously, working experience does not increase one for one with age. More educated people are older when they enter the labour market. 


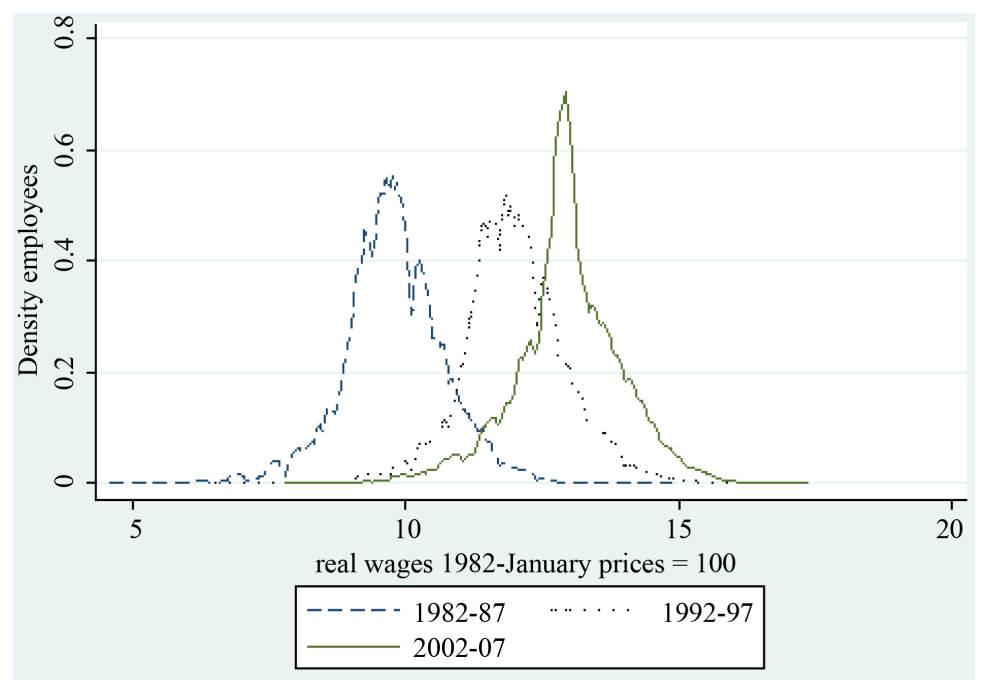

Figure 8. Kernel function: Cohort aged 42 - 47.

Table 2. Regression analysis of real wages function.

\begin{tabular}{|c|c|c|c|c|}
\hline Independent variable & Wage level [1] & Wage level [2] & Wage level [3] & Wage log [4] \\
\hline Experience & 819.157 & 819.208 & 830.701 & 0.097871 \\
\hline [Error standar] & [1.537] & [1.539] & [1.5113] & [0.000077] \\
\hline Experience squared & -9.5042 & -9.504 & -9.6605 & -0.00111 \\
\hline [Error standar] & {$[0.01596]$} & {$[0.01596]$} & [0.0158] & $8.39 \mathrm{E}-07$ \\
\hline Education level & 538.334 & 538.44 & 537.095 & 0.00071 \\
\hline [Error standar] & [2.191] & [2.197] & [2.1679] & {$[0.000016]$} \\
\hline Education $\times$ experience & & -0.0047 & & \\
\hline [Error standar] & & [0.0068] & & \\
\hline Unemployment rate & -216.267 & -216.27 & 24.063 & -0.015768 \\
\hline [Error standar] & [1.197] & [1.197] & [0.6861] & {$[0.00007]$} \\
\hline Capital accumulation & 1326.142 & 1326.156 & & 0.082519 \\
\hline [Error standar] & {$[6.728]$} & [6.729] & & $3.83 \mathrm{E}-04$ \\
\hline Machinery accumulation & & & 2616.621 & \\
\hline [Error standar] & & & [9.0269] & \\
\hline Economic openness & 105.098 & 105.098 & 27.315 & 0.006633 \\
\hline [Error standar] & [0.6925] & [0.69252] & {$[0.7736]$} & $3.95 \mathrm{E}-05$ \\
\hline Constant & -16934.81 & -16936.03 & -13747.41 & 6.96052 \\
\hline [Error standar] & [35.221] & [35.266] & [22.456] & [0.00199] \\
\hline $\mathrm{R}^{2}$ & 0.327 & 0.327 & 0.332 & 0.708 \\
\hline
\end{tabular}

Source: DANE, household surveys.

$$
\omega(\text { schooling, experience })=\alpha+\rho_{s} \text { schooling }+\beta_{0} \text { experience }+\beta_{1} \text { experience }{ }^{2}+\text { other variables }+e
$$

That equation is nearly the standard form of the Mincer model that regress real wages according to a constant linear term in years of schooling and a quadratic term in years of labour market experience (Heckman, Lochner and Todd [16]). Additionally other variables are included in the regression, as mentioned above. The dependent 
variable in Equation (2) is the level, not the log, as is used by Faber and Gibbons [17]. The assumption behind it is that the real wages paid to workers are equal to the output that it is expected that they produce given the information available for employers regarding education and work experience. Real wages are also tested in log expression.

There are four regression specifications presented in Table 2. The estimation technique is a fixed effects panel data, including the effects for 80 cohorts groups and the results show the usual strong positive relationship of wages with experience and education. The parameter values are those expected for individuals. Those obtained in the regressions [1] [2] [4] are statistically significant and the signs are as expected: positive for age, education, capital accumulation, and economic openness; and negative for the unemployment rate.

In regression [3] the signs are as may be expected and are positive for capital in terms of machines, instead of the total accumulated capital and economic openness; but the unemployment rate sign is the opposite, positive, nevertheless that all estimated parameters are statistically significant.

There is the assumption in the previous econometric model that the working experience profiles are parallel and diverge from the schooling levels (Heckman, Lochner and Todd [16]; and Faber and Gibbons [17]), and this result is showed in regression [2], in which the parameter of the interaction of education and experience is no statistically significant different from zero ( $p$-value $>0.50$ using a two-tailed test).

As wage function is estimated in levels rather than logs, the coefficient of the quadratic function of age cannot be compared directly with standard estimates of age coefficients. However, the proportional effect of work experience on real wages starts with an annual growth rate of approximately 8 percentage, and then decreases progressively until reaching an annual growth rate of 1.7 percentage, which is approximately the range found in the estimation of real wage function in logs, that is regression [4].

Capital accumulation has the greatest effect on the behaviour of real wages when the fixed effects are the cohorts. Economic openness is positive in all cases, but its impact is relatively low. In the last two decades, Colombia has undergone a process of trade liberalization, and this is likely to have positive consequences for the returns on human and physical capital. Trade liberalization in a developing country leads to more technology transfer that increases the demand for skilled labour (Pissarides [18]).

\section{An Example with a Simple Model}

In this section a particular set of simplifications are introduced to provide greater clarity on concerning how each cohort makes decisions regarding the inter-temporal income during the life-cycle. Thus, a simple overlapping generation model is constructed in order to explain how a representative cohort makes the consumption and saving decisions, regardless of unforeseen difficulties (de la Croix and Michel [19]).

The theoretical model is constructed with the following four characteristics:

1) Workers live for twelve periods. In the first nine ones they are active in the labour market; while the last three ones they receive a pension together with any accrued capital plus its returns (Hviding and Mérette [20]). In this sense each period represents a five-year interval.

2) Twelve generations coexist simultaneously in each period, and each has the same life expectancy. The number of people entering the labour market in period $t$ grows at rate $n$ with respect to the immediately preceding generation.

3) Increasing labour productivities are attributable to technological improvements in physical capital, higher levels of labour skills and job apprenticeships.

4) Workers contribute to a pension fund during their working life. To simplify the analysis it is assumed that individuals do not pay taxes; as a consequence, the existence of government is abstracted.

The domestic output, which is consumed or added to the capital stock, is modelled as a Cobb-Douglas function, where the factors of production are capital and different degrees of skilled labour, being the less skilled workers the youngest while more skilled workers are middle-aged. Capital goods are traded before investment, but not later. Since market factors are competitive, demand goes to the point where marginal revenue equals the cost of acquisition.

For each set of equations related below, the subscript $t$ is time and $T$ is both the number of cohorts and the age for each. $T_{1}$ represents the nine working periods and $T_{2}$ the three pension periods (Equation (3)), so that

$$
T=T_{1}+T_{2} \text {. }
$$


There is the problem of determining for which working period of nine $\left(T_{1}\right)$ capital replaces unskilled workers; and from that period of time the capital is complementary to skilled workers. For practical purposes I shall consider that workers are unskilled for their first five periods, and afterwards they are complementary to capital.

The model structure is divided into three blocks of equations. These are: economy of a representative cohort, the pension fund, and the productive sector.

\subsection{Economy of a Representative Cohort}

The representative cohort is expressed by an inter-temporal utility function for $T$ periods. Working life starts, say, at age 17. Individuals under that age are supposed to be economically dependent on their parents, but they are not an additional financial burden for them and do not obtain any utility in these years.

Workers retire from the labour market at the end of $T_{1}$ and then they are not occupationally active for the following three periods. The representative cohort uses both the accrued real assets and the savings accumulated in the pension fund to finance the consumption during the three nonworking periods $\left(T_{2}\right)$.

People, who belong to a representative cohort, are rational and have perfect prediction, and their inter-temporal utility function is expressed as

$$
u_{t+g-1}=\frac{c_{t+g-1}^{1-\beta}}{1-\beta}, \beta \neq 1
$$

where $c_{t+g-1}$ is the consumption of cohort $g$, in period $t . \beta$ is a parameter that allows to obtain a wide range of different individual behaviour ${ }^{8}$. The inter-temporal utility function written for a particular cohort during her life cycle is:

$$
U_{t}=\sum_{g=1}^{T 1+T 2}\left(\frac{1}{1+\rho}\right)^{g} u_{t+g-1}
$$

being $\rho$ the rate of time preference.

Each cohort maximizes an utility function (Equation (5)) when choosing the optimal inter-temporal consumption paths, without exceeding the inter-temporal income.

The representative cohort born without wealth ( $T=0$ period). The cohort wealth is represented by the physical capital $\left(k_{t}\right)$ and financial assets $\left(f_{t}\right)$, where the last is related to the pension fund. It is further assumed that people do not left inheritances at the end of their lives. Individuals receive their labour income and the capital returns during their working life ( $T_{1}$ periods), but in the last three periods the earnings are the accumulated capital and the returns, and pension payments. Thus, workers accrue assets during their active working lives, but those assets are consumed when they retire from the labour market.

Households' inter-temporal budget constraint, during their working life $\left(T_{1}\right)$, is:

$$
k_{t+g}=\left(1+r_{t+g-1}\right) k_{t+g-1}+(1-\varphi) \omega_{t+g-1}-c_{t+g-1} ;
$$

where $k$ is the per-capita capital stock; and $r$ and $\omega$ are the interest rate and wages valuated in real terms. The ratio $(\varphi)$ is the proportion of the labour income that is accumulated in a pension fund. The constraint during the retirement period is

$$
k_{t+g}=\left(1+r_{t+g-1}\right) k_{t+g-1}+R-c_{t+g-1} .
$$

$R$ is the pension payment in each retirement period, and these payments are equals in each period (annuity). Constraint 6 applies for $g=1,2, \cdots, 9$; where households consume the difference between their incomes and the amount of resources allocated for both the capital accumulation employed in the production and their contributions to the pension fund. Constraint 7 applies when households leave the labour market $(g=10, \cdots, 12)$, where their consumption is financed by the pension, the accrued capital and the respective returns.

Household's consumption in the last period $(T=12)$ is equal to the sum of the residual capital $\left(k_{12}\right)$, the last pension payment $(R)$ and the capital returns $\left(r_{12} \cdot k_{11}\right)$. That result is written as

\footnotetext{
${ }^{8}$ According to the Arrow-Pratt measure of relative risk aversion, the utility function has a preference value of $\beta$. It is known that if this value is positive, negative or zero indicates that the agent is averse, risk-loving or neutral to the risk.
} 


$$
C_{12}=k_{12}+R+r_{12} \cdot k_{11} \text {. }
$$

\subsection{Pension Fond}

There is the restriction that the aggregated value of the pension fund contributions by workers at the end of working period $S_{T 1}$ must be equal to the total of pension payments. This is written as

$$
S_{T 1}=\sum_{t=1}^{T 1} \varphi \omega_{t+g-1}\left(1+r_{t+g-1}\right)^{T_{1-t}}=\sum_{t=T_{1}+1}^{T_{2}} R
$$

where $R$ is a pension constant that is paid in each retirement period, and replaces the labour income. The mathematical expression for calculating $R$ is

$$
R=S_{T_{1}} \cdot r_{t+g-1} \cdot\left(1-\left(1+r_{t+g-1}\right)^{-T_{2}}\right)^{-1} .
$$

\subsection{Production Sector}

This sector is represented by a Cobb-Douglas function with constant returns to scale, which allows calculate the capital, skilled and unskilled labour prices in $t$. The unskilled workers $(L)$ are the aggregation of them in the first five periods. The qualified workers $(S)$ are the aggregation of them over the next four periods. This function for period $t$ is

$$
Y_{t}=A\left(L_{t}+\eta \cdot K_{t}\right)^{a} S_{t}^{1-a} \text {; where } L_{t}=\sum_{g=1}^{5} L_{t, g} \text {, and } S_{t}=\sum_{g=6}^{9} S_{t, g} .
$$

The term $A$ is the total factorial productivity in the production function. The factors $L$ and $K$, with elasticity $\eta_{L, K}<0$, are combined with $S$ in the Cobb-Douglas production function to produce $Y$. The parameter $\eta$ measures the efficiency of the capital stock (Kotlikoff and Sachs [2]). Given $L, S$ and $K$, an rise in $\eta$ must reduce the unskilled labour productivity in relation to the skilled labour productivity, that is

$$
\frac{\partial}{\partial \eta} \frac{\partial Y_{t}}{\partial L_{t}}<0 ; \text { and } \frac{\partial}{\partial \eta} \frac{\partial Y_{t}}{\partial S_{t}}>0 .
$$

The production factor prices are set by the marginal productivities. The capital price $\left(r_{t}\right)$

$$
r_{t}=A \alpha \eta\left(1+\eta k_{t}\right)^{\alpha-1} s_{t}^{1-\alpha},
$$

the real wage $\left(\omega_{u, t}\right)$ for unskilled workers

$$
\omega_{u, t}=A \alpha\left(1+\eta k_{t}\right)^{\alpha-1} s_{t}^{1-\alpha},
$$

and the real wages $\left(\omega_{s, t}\right)$ for skilled workers

$$
\omega_{s, t}=A(1-\alpha)\left(1+\eta k_{t}\right)^{\alpha} s_{t}^{-\alpha} .
$$

where $k_{t}$ and $s_{t}$, in units of unskilled labour, are defined as

$$
k_{t}=\frac{K_{t}}{\sum_{g=1}^{5} L_{t, g}} \text {; and } s_{t}=\frac{S_{t}}{\sum_{g=1}^{5} L_{t, g}} .
$$

The estimated parameters in the quadratic expression for ages in Regression [1] are used to calculate the different levels of real wages that a typical worker would get during her life-cycle, taking the above factor prices (Equations (12)-(14) as averages in their states of unskilled or skilled. Real wages for different ages of workers are calculated with the quadratic expression

$$
\omega_{g}=148+819.16 \cdot T_{1}-9.504 \cdot T_{1}^{2} .
$$

\subsection{Simulation}

The simulations are run under the assumption that consumers take their optimal decisions, according to the Euler 
equation (Heer and Maußner [21]), that is

$$
c_{T+g-1}=\left[\frac{1+\rho}{1+r_{t+g}}\right]^{\frac{1}{\beta}} C_{t+g} .
$$

The simulations for factor prices, consumption, and capital accumulation for a representative cohort are related in Figure 9, using the Newton-Raphson Method and the following parameter values: $\alpha=0.3 ; \beta=0.9 ; \rho=$ $0.08 ; \varphi=0.05 ; \gamma=0.05$; and $n=0.064$.

The experiment is performed as follow. First, a value of 0.7 is assigned to capital efficiency $(\eta)$, and then this value is increased to 1.3 in order to compare the effects generated on the trajectories of wages, consumption, and the capital accumulative curve.

The four graphs in Figure 9 show the paths of the variables for a value of $\eta$ equal to 0.7, when each period represents five years. Wages follow a linear upward trend and consumption also shows a growing linear trend thanks to pronounced dissaving until de seventh generation. The real interest rate is 11.3 percentage and is calculated as a weighted average for the whole economy.

The next four graphs in Figure 10 illustrate the results when the value of $\eta$ is equal to 1.3. Figure 10(a) presents higher real wages from the seventh to the ninth cohorts, corresponding to skilled workers. This result allows those cohorts of skilled workers to increase their consumption levels (Figure 10(c)). Capitalization levels in the economy (Figure 10(d)) fall less for the first cohorts of unskilled workers, if this variable is compared with its similar in Figure 9(d), but capital levels for cohorts of skilled workers are clearly higher (Figure 10(d)). All previous results are consistent with a real interest rate of 23.6 percentage.

Therefore there is a clear difference among the results that are getting if the capital efficiency $(\eta)$ increases. The real wage gap between skilled and unskilled workers increases, consumption levels for workers with higher skill levels improve substantially, and simultaneously the dynamics of capital accumulation is higher. The above results are consistent with upper real interest rate.

\section{Conclusions}

The basic argument of this paper is that there is a close relationship between real wages earned, productivity and economic growth through capital accumulation. The hypothesis of the life-cycle theory, in its simplest version, shows that people tend to save during their working lives to finance their consumption when they retire from the labour market. However, the accumulation of capital and the introduction of increasingly sophisticated machines

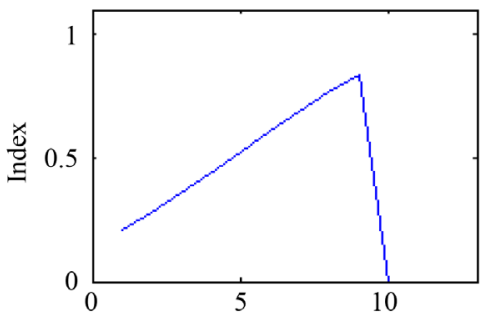

(a)

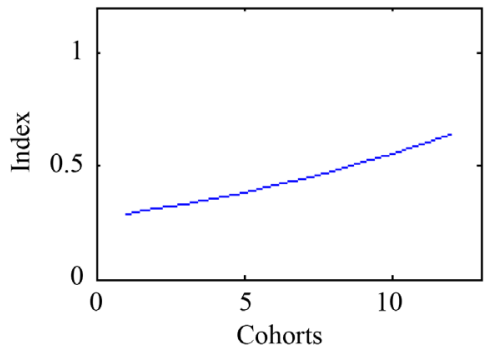

(c)

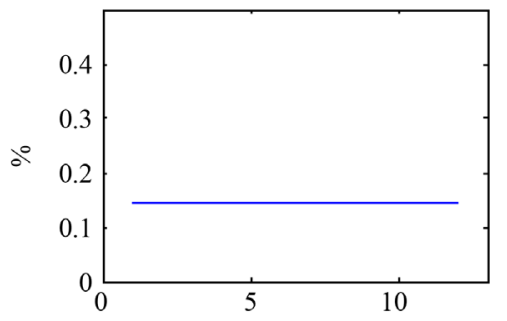

(b)

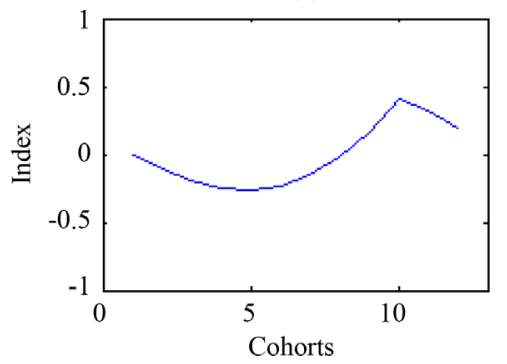

(d)

Figure 9. Simulations if the capital efficiency is low ( $\eta=0.7$ ). (a) WAGE, $\eta=0.7$; (b) INTEREST, $\eta=0.7$; (c) CONSUMPTION, $\eta=0.7$; (d) CAPITAL, $\eta=0.7$. 


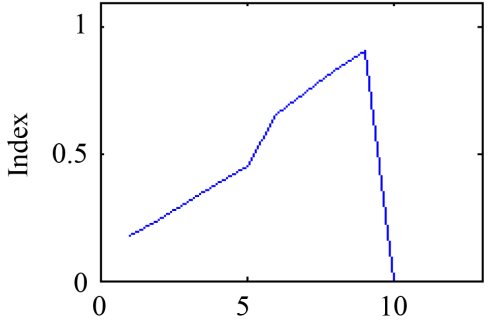

(a)

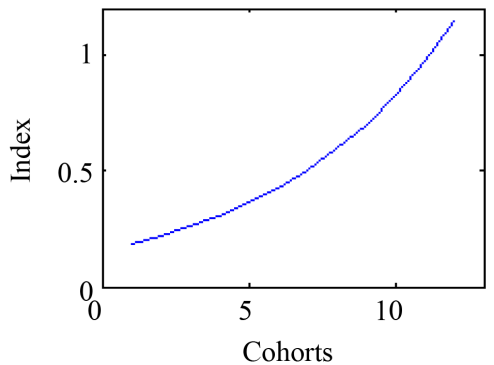

(c)

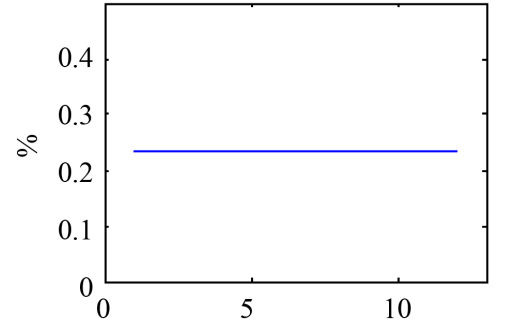

(b)

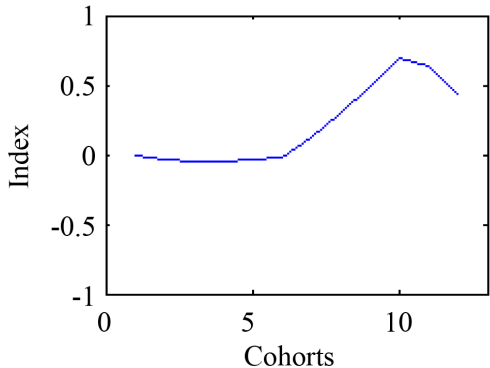

(d)

Figure 10. Simulations if the capital efficiency is high ( $\eta=1.3$ ). (a) WAGE, $\eta=1.3$; (b) INTEREST, $\eta=1.3$; (c) CONSUMPTION, $\eta=1.3$; (d) CAPITAL, $\eta=1.3$.

tend to replace less qualified workers, and thereby the gap between real wages of skilled relative to unskilled workers increases.

The hypothesis of the growing gap between the real wages of unskilled workers and those of highly skilled workers is studied empirically, and this phenomenon is simulated under the construction of a simple overlapping generation model. This issue is addressed with the consideration that young workers are less skilled and they are replaced by the introduction of more sophisticated machines in the production system, and, thus, real wages become relatively lower in comparison with more skilled workers. In contrast, the greater accumulation of capital in economies generally favours people of older ages and qualifications, who also tend to be owners.

These inequalities are increasing over time, as unskilled workers increasingly require greater financial resources in order to obtain qualifications and this is in sharp contrast with the deterioration of workers' earnings. This aspect was simulated in an overlapping generation model, in which the parameter that relates to the efficiency levels of capital increases. Increased efficiency of capital increases levels of consumption and capital accumulation, thereby increasing the differences between the real wages of skilled relative to unskilled workers.

There are basically three empirical results from the Colombian household surveys for the period 1982-2007:

1) The curve shape of the age profiles by cohorts is the well-known standard life-cycle. The workers' productivities increase until the age of fifty, and then they tend to fall. In general, the hump shape of the productivity curve is the same for periods of high and low economic growth. The shape of this curve also explains the aggregate levels of savings-investment in the economy.

2) Cohorts of workers, who born before the 1950s, show increasing productivities. People, who were born from the 1950s to the late 1970s, exhibit decreasing productivities. Subsequent cohorts recover earlier productivity levels.

3) Colombia's labour structure has undergone important changes in the period 1982-2007. A demographic transition has tilted the balance from a relatively young population to an older one. This phenomenon has led middle-aged workers to increase their share in the labour market. Older workers have continuously increased their share in the labour demographic structure. Unfortunately, these structural changes have not resulted in significant increases in productivity levels.

The industrial sector has not been a leading sector in the period from 1982 to 2005. In some episodes its labour productivity and real wages have been lagged behind in relation to the service activities. In general, the pattern of industry real wages is similar to that of the economy where older cohorts have the highest wages relative to the younger cohorts.

For the most recent years, for which the Colombian economy faces unfavourable external shocks, the dynam- 
ics of the economy would tend to be slower. This economic result would have adverse effects in terms of income inequalities, especially against younger workers.

\section{Acknowledgements}

I am deeply indebted to Àlvaro Zarta for his useful comments. I thank the financial support from the Tadeo Lozano University of Bogotá. This paper has been benefited from the seminars that were held in the same university and the National Department Planning.

\section{References}

[1] Guataquí, J.C., García, A. and Rodríguez, M. (2009) Estimaciones de los determinantes de los ingresos laborales en Colombia con consideraciones diferenciales para asalariados y cuenta propia. Documentos de Trabajo, 70, Universidad del Rosario. http://dx.doi.org/10.2139/ssrn.1492999

[2] Kotlikoff, L.J. and Sachs, J.D. (2012) Smart Machines and Long-Term Misery. NBER Working 18629. http://dx.doi.org/10.3386/w18629

[3] Baldwin, R.E. and Martin, Ph. (1999) Two Waves of Globalization Superficial Similarities, Fundamental Differences. NBER Working 6904. http://dx.doi.org/10.3386/w6904

[4] Williamson, J.G. (2002) Winners and Losers over Two Centuries of Globalization. WIDER Annual Lecture 6.

[5] The Economist (2014) Special Report. The World Economy. October 4th.

[6] Becker, G.S. (1975) A Theoretical and Empirical Analysis, with Special Reference to Education. 2nd Edition, Columbia University Press, New York. http://dx.doi.org/10.2307/2229541

[7] Smeeding, T.M. and Sullivan, D.H. (1998) Association Generations and the Distribution of Economic Well-Being: A Cross-National View. The American Economic Review, 88, 254-258. http://dx.doi.org/10.2307/1056994

[8] Beaudry, P. and Green, D.A. (2000) Cohort Patterns in Canadian Earnings: Assessing the Role of Skill Premia in Inequality Trends. The Canadian Journal of Economics, 33, 907-936. http://dx.doi.org/10.1111/0008-4085.00047

[9] Berloffa, G. and Villa, P. (2010) Difference in Equivalent Income across Cohorts of Households: Evidence from Italy. The Review of Income and Wealth, 56, 693-714. http://dx.doi.org/10.1111/j.1475-4991.2010.00403.x

[10] Deaton, A. and Paxson, Ch. (2000) Growth and Saving among Individuals and Households. The Review of Economics and Statistics, 82, 212-225. http://dx.doi.org/10.1162/003465300558740

[11] Deaton, A. and Paxson, C. (2000) Growth, Demographic Structure, and National Saving in Taiwan. Population and Development Review, 26, 141-173.

[12] Mesa, F., Zarta, Á. and Sánchez, G. (2007) Deuda pública y Crecimiento Económico en Colombia como una Aproximación de Generaciones Traslapadas. Revista de Relaciones Internacionales, Estrategia y Seguridad, 2, 61-89.

[13] Attanasio, O. and Székely, M. (2002) An Introduction to Household Decision-Making: How to Interpret the Data. In: Attanasio, O. and Székely, M., Eds., The Family in Flux: Household Decision-Making in Latin America, Inter-American Development Bank, Washington DC.

[14] Deaton, A. (1997) The Analysis of Household Surveys: A Microeconometric Approach to Development Policy. The World Bank and the Johns Hopkins University Press, Baltimore. http://dx.doi.org/10.1093/ajae/82.3.780

[15] Biddle, J.E. (2014) The Cyclical Behaviour of Labor Productivity and the Emergence of the Labor Hoarding Concept. Journal of Economics Perspectives, 28, 197-212. http://dx.doi.org/10.1257/jep.28.2.197

[16] Heckman, J.J., Lochner, L.J. and Todd, P.E. (2003) Fifty Years of Mincer Earnings Regressions. NBER Working 9732. http://dx.doi.org/10.3386/w9732

[17] Farber, H.S. and Gibbon, R. (1996) Learning and Wage Dynamics. The Quarterly Journal of Economics, 111, 10071047. http://dx.doi.org/10.2307/2946706

[18] Pissarides, C.A. (1997) Learning by Trading and the Returns to Human Capital in Developing Countries. The World Bank Economic Review, 11, 17-32. http://dx.doi.org/10.1093/wber/11.1.17

[19] De la Croix, D. and Michel, P. (2002) A Theory of the Economic Growth: Dynamics and Policy in Overlapping Generations. Cambridge University Press, Cambridge. http://dx.doi.org/10.1017/cbo9780511606434

[20] Hviding, K. and Marcel, M. (1998) Macroeconomic Effects of Pension Reforms in the Context of Ageing Populations: Overlapping Generations Model Simulations for Seven OECD Countries. OECD, ECO/WKP 98, 14. http://dx.doi.org/10.1787/638376177076

[21] Burkhard, H. and Maußner, A. (2005) Dynamic General Equilibrium Modelling: Computational Methods and Applications. Springer, Berlin. http://dx.doi.org/10.1007/b138909 